\title{
Fracture mechanics of mollusc shells
}

\author{
Michael B.Cortie, ${ }^{\mathrm{a},{ }^{*}}$ Katie E. McBean, ${ }^{\mathrm{b}}$ Margaret M. Elcombe \\ anstitute for Nanoscale Technology, University of Technology Sydney, Australia \\ ${ }^{b}$ Microstructural Analysis Unit, University of Technology Sydney, Australia \\ ${ }^{c}$ Bragg Institute, Australian Nuclear Science and Technology Organisation, PMB 1, NSW, Australia
}

Elsevier use only: Received date here; revised date here; accepted date here

\begin{abstract}
The shape and structure of the shells of molluscs has attracted considerable attention. One aspect of interest is the comparatively high resistance to fracture of these shells. It is known that they are composite structures of aragonite, other calcereous materials, and up to $5 \%$ by volume of protein 'glue'. A large component of their toughening derives from crack tip blunting, deflection and closure, concepts well-known from the field of fracture mechanics. However, the possibility that they might also derive a measure of toughening from a residual stress distribution has been generally overlooked, although Illert first raised this over a decade ago. The optimum situation would be when the inner surface of the shell is maintained in a state of tensile stress, while the outer layers are in the necessarily counter-balancing compressive state. We have examined this hypothesis using a combination of neutron diffraction and scanning electron microscopy and find that it is certainly feasible. However, a definitive proof will require a diffraction study at higher resolution. ㅇ 2006 Elsevier Science. All rights reserved
\end{abstract}

Keywords: Mollusc shell, Fracture, Residual stress, Neutron diffraction

The mathematically regular spirals of mollusc shells (e.g.[1-3] and references therein) and their comparatively high resistance to fracture (e.g. [4,5]) have long been of interest. The mechanical strength has resulted from the evolutionary interplay between predation on the species and its need to ensure survival and fecundity [6]. The fracture toughness of $\mathrm{CaCO}_{3}$ (out of which mollusc shells are principally comprised) is $0.9 \mathrm{MN} . \mathrm{m}^{-1.5}$, which is similar to ordinary glass [7]. However, mollusc shells are vastly more durable and tougher than if made from glass. Research has slowly revealed the reasons. Firstly, shells are composite structures of aragonite, other calcareous materials such as calcite, and up to $5 \%$ by volume of protein 'glue' known as conchiolin. A large component of the toughening derives from the unique aragonitic microstructure of the nacre layer which facilitates crack tip blunting, deflection, closure and bifurcation- concepts well known from the field of fracture mechanics. Moreover, it has been found that the nacreous structure can also undergo inelastic deformation [4], which is helpful. Finally, it has recently been claimed that aragonite platelets themselves are nanostructured in such a way as to permit some internal

\footnotetext{
* Corresponding author.

E-mail address: michael.cortie@uts.edu.au (M. Cortie)
}

plastic deformation [5]. Although these microstructural mechanisms certainly provide toughening, it might also be worthwhile to consider an often overlooked proposal made over a decade ago by Illert $[8,9]$. In this work it was shown that the spiral form of the mollusc shell can be mathematically derived from Hooke's law of elasticity applied to a 'clock-spring'. This result suggests that stress state and spiral shape in a mollusc shape may be related. In a 'clock-spring', the state of stress in the wound-up form is tensile. If the spring is relaxed, then it unwinds and expands in size and the stress relaxes [10]. If Illert's claim is true, then there should be evidence for such a residual tensile stress state in the whole shells of molluscs but not in crushed material. 
We have investigated the possible existence of such residual stresses in shells of the intertidal marine mollusc Austrocochlea constricta, a member of the Trochidae ('top shells'). Diffraction with $1.884 \AA$ Á neutrons was used for this analysis, which permitted the characterization of all parts of an intact shell, unlike X-rays which probe only surface layers. The strong crystallographic texture of the aragonite plates of the nacreous inner layer presented both a challenge and an opportunity. The challenge was to obtain randomized patterns. This was accomplished by presenting the whole shells to the neutron beam inside a spherical aluminium 'spinner', which was levitated by jets of compressed air and designed to randomly and freely rotate in all directions. The opportunity offered by the texture, which is strongly correlated to the growth vectors of the apertural lip, is that it offers, in principle, a method to differentiate residual stress along the [001] basal pole from other stresses. The base-line comparator in this work was a sample of the same type of shells, but pulverized to relieve all macroscopic residual stresses. This was measured in a rotating, cylindrical sample holder. Both grit and whole shells were prepared less than a week prior to measurement by removal of the soft parts of the mollusc by boiling in water for 30 seconds. The diffraction patterns of the whole shells appeared to be of randomly orientated crystallites, as desired, proving that the spinner had worked correctly. Xray analysis of powdered whole shells was also performed with $\mathrm{Cu} \mathrm{K \alpha}$ radiation in order to verify the phase composition.

The microstructures of the shells were examined after mounting samples in resin, followed by metallographic polishing, and a final etch in $0.1 \mathrm{M}$ ethylenediaminetetraacetic acid (EDTA) solution for 30 seconds.

Scanning electron microscopy revealed that the structure of the shells of this species shares the generic features of other molluscs. There is an inner nacreous layer comprised of platelets of aragonite that are arranged in a tessellated lamellar structure, growing at first as conical piles (Figure 1), until completely tessellated (Figure 2), and an outer layer of very different structure (Figure 3). The aragonite lamellae were of the order of $6900 \mathrm{~nm}$ long in the polished sections examined, similar to those of other molluscs, but their true thickness should not be inferred from Figure 2 since the plane of polishing was not necessarily parallel to their common [001] pole. The outer layer found in the present work is similar in morphology and appearance to the 'calcitic' outer layer widely reported for other species $[4,5]$.

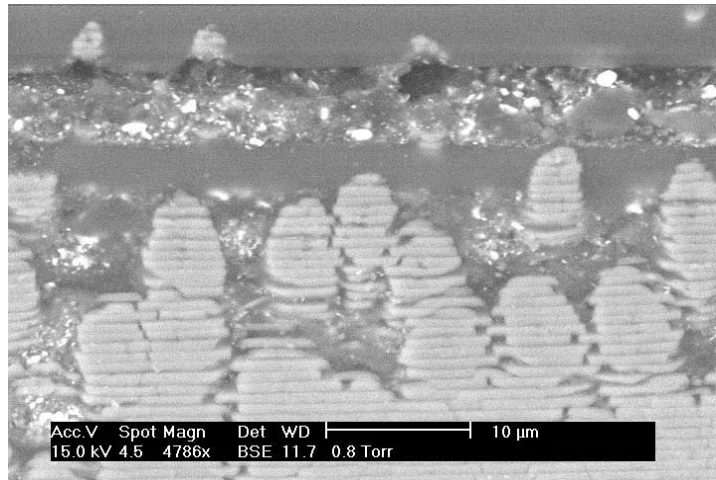

Figure 1. Microscopic cross section through lip (growth edge) of shell of Austrocochlea constricta, showing characteristic cones of newly formed aragonite plates in strong preferred orientation with respect to the whorl surface (top).

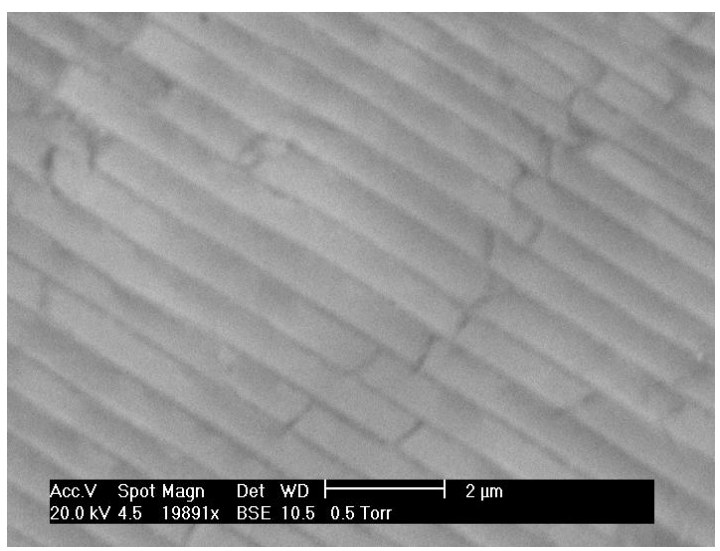

Figure 2. Close-up view of completed, columnar, microstructure of aragonite plates.

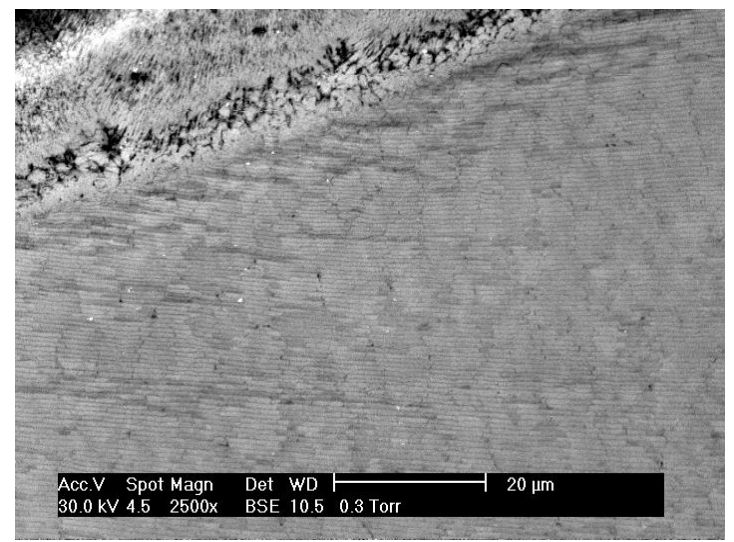

Figure 3. Intersection of tessellated aragonitic layer (bottom and right) with non-lamellar surface layer (top left) 
Curiously, neither neutron nor X-ray diffraction revealed any detectable calcite content in these samples, indicating that the outer layers visible in Figure 3 contained less than $2 \%$ calcite, contrary to statements in the literature. Rietveld analysis of the data (Figure 4) produced satisfactory results provided that the presence of the Al container was taken into account in the case of the whole shells, and an $8 \%$ preferred orientation was taken into account in the case of the shell grit. The latter effect may have been due to the packing down of flake-like grit in the sample holder used.

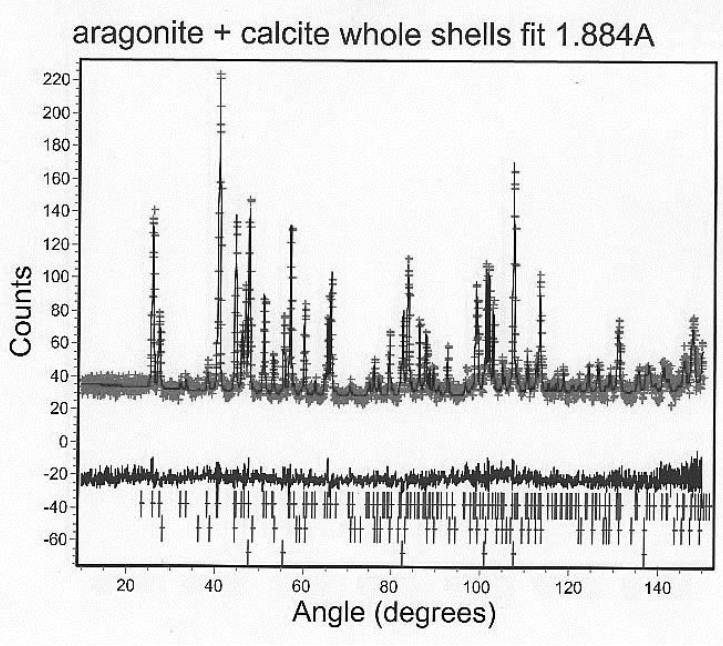

Figure 4. Results of the Rietveld analysis of the whole shells, showing a satisfactory agreement between model and data. The observed data are the crosses, the continuous line through them the calculated fit. Below that is the difference plot and finally there are the peak markers for aragonite, calcite and aluminium.

The lattice parameters generated by the Rietveld analysis are listed in Table 1 . The small differences between the two sample types are at the level of experimental error of the technique used. Nevertheless, these figures can certainly be used to put an upper limit on the level of stress that might exist in the nacreous, aragonitic portion of an empty shell. Taken at face value, they imply an elastic dilation of $7 \times 10^{-3} \%$ along the $a$ direction of the aragonite plates, and of $6 \times 10^{-3} \%$ in the $c$ axis direction with respect to the grit.

Table 1. Lattice parameters of aragonite in nacre of shell

\begin{tabular}{|c|c|c|}
\hline Axis & grit & whole shell \\
\hline$a, \AA$ & $5.7536(2)$ & $5.7540(3)$ \\
\hline$b, \AA$ & $4.9663(1)$ & $4.9663(2)$ \\
\hline$c, \AA$ & $7.9607(2)$ & $7.9612(4)$ \\
\hline
\end{tabular}

The Young's modulus of molluscan nacre has been measured to be in the range of about 70 to $80 \mathrm{GPa}$ [4,5], so these values of strain, if valid, would correspond to internal stresses of 4 or $5 \mathrm{MPa}$. However, both are tensile in nature, suggesting that there would have to be a significant counter-balancing compressive stress in the outer layers of the shell. The breaking stress of nacre in other species has been determined to be of the order of 200 to $250 \mathrm{MPa}$ [4]. The postulated tensile residual stresses are therefore of the order of $2 \%$ of the failure stress.

However, as ably discussed by Vermeij, attack on the shell of a mollusc will usually be initiated on the exterior layers [6]. If there was a tensile stress distribution in the nacreous layers, it must necessarily be balanced by a compressive stress in the outer layers. This would have a beneficial influence on crack initiation and propagation from the exterior. In possible support for this hypothesis we note that calcite has a density of $2.71 \mathrm{~g} . \mathrm{cm}^{-3}$, while aragonite has a density of $2.93 \mathrm{~g} . \mathrm{cm}^{-3}$. In situ conversion of freshly deposited amorphous $\mathrm{CaCO}_{3}$ (e.g. see Bolze et al [11]) to aragonite on the inner surface would produce the necessary residual stress distribution naturally, with the bulk of the shell exhibiting Illert's tensile stress. Furthermore, the blocky microstructure of the aragonitic layers ensures both deflection and division of tensile cracks, providing it with superior toughness in this mode, compared to the outer layers which are brittle in tension. We surmise that this is no accident.

\section{Acknowledgement}

The authors thank ANSTO for beam time funded by AINSE grant 04033, and Mr M. Berkahn of UTS for X-ray diffraction. MC acknowledges useful discussions over the years with C. Illert.

\section{References}

[1] D'A.W. Thompson, On Growth and Form, Cambridge University Press, Cambridge 1942.

[2] M.B. Cortie, M.B. The form, function and synthesis of the molluscan shell, in Spiral Symmetry, eds. I.Hargittai and C.A.Pickover, World Scientific Publishing Co, Singapore, 1992. pp.369- 387.

[3] M.B. Cortie, Computers \& Graphics 17(1), (1993) 79.

[4] R.Z. Wang et al., J. Mater. Res. 16(9) (2001) 2485.

[5] X. Li et al., NanoLetters 4(4) (2004) 613.

[6] G.J. Vermeij, A Natural History of Shells, Princeton universuty Press, Princeton, USA, 1993.

[7] M.F. Ashby and D.R.H. Jones, Engineering Materials, Pergamon, Oxford, 1980.

[8] C. Illert, Il Nuovo Cimento 9D (1987) 791.

[9] C. Illert and R.M. Santilli, Foundations of Theoretical Conchology, Hadronic Press Palm Harbour Florida 1995.

[10] R.H. Warring, Spring Design and Calculation, Model \& Allied Publications, Hempstead, UK 1973.

[11] J. Bolze et al., Journal of Colloid and Interface Science 277, (2004) 84. 